\title{
Labeling strategies to overcome the problem of niche markets for sustainable milk products: The example of pasture-raised milk
}

\author{
S. Kühl, ${ }^{1}$ B. Gassler, and A. Spiller \\ Department of Agricultural Economics and Rural Development, Marketing of Food and Agricultural Products, University of Göttingen, \\ Platz der Göttinger Sieben 5, 37073 Göttingen, Germany
}

\begin{abstract}
Pasture-raised milk is gaining in importance in some European countries and in the United States. The production of pasture-raised milk is linked to higher costs, as the milk is normally collected and processed separately from conventional barn milk. This could hinder the production of sustainable milk products. We discuss alternative labeling strategies that allow the mixing of pasture-raised (sustainable) and conventional milk to reduce costs and break free from the current niche market. The lower price would allow for more pasture-raised milk to be produced and enter the mainstream market. The aim of this study was to analyze consumers' willingness to pay for alternative labeling types using a discrete choice experiment with 1,065 German milk buyers. The 2 alternative labels, besides the classical labeling approach, are based on the mass balance approach (at least $50 \%$ pastureraised milk in a package) and cause-related marketing (support of farmers who keep their cows on pasture). The discrete choice experiment was combined with a cluster analysis to get a deeper understanding of the buying behavior of the diverse consumer segments for milk. We found that all consumer groups prefer the classical label where products are segregated but also understand the benefits of cause-related marketing. The average consumer was willing to pay €0.50 more for pasture-raised milk certified with the classical label and $€ 0.38$ more for pasture-raised milk labeled with a cause-related marketing claim. However, differences between the clusters are strong: The smallest cluster of ethically involved consumers $(15 \%)$ is willing to pay the highest premiums, especially for the classical label. Cause-related marketing is an interesting alternative for involved buyers under price pressure (41\%), whereas the mass balance approach is little understood and thus less valued by consumers. From our results we
\end{abstract}

Received September 14, 2016.

Accepted February 21, 2017.

${ }^{1}$ Corresponding author: skuehl@gwdg.de concluded that cause-related marketing (in our case, the support of pasturing of dairy cows) can be useful for dairies for which it is not efficient to collect and process products separately. This approach is furthermore suitable for reaching consumers who are mainly interested in altruistic issues but at the same time are more price sensitive, as this labeling strategy does not need separate collection and processing and can thereby be marketed at a lower price.

Key words: mass balance certification, alternative labeling strategy, consumer behavior, discrete choice experiment, pasture-raised milk

\section{INTRODUCTION}

Pasture-raised milk is gaining in importance in Europe and the United States. Typically, this kind of milk is sourced completely from cows with access to pasture. This implies that the milk has to be collected and processed separately from conventional barn milk, leading to higher costs for dairy companies (Dehue et al., 2007). The additional production costs have to be covered by sales, which in turn depend on higher consumer prices. However, high prices could act as purchasing barriers (McEachern and Schröder, 2002). Thus, segregation costs could be the reason why certified products remain in niche markets as larger, low cost-oriented producers expect cost disadvantages (OECD, 2004).

Further costs arise from the bonus payments farmers often receive to motivate them to follow certain production standards (Schreiner and Latacz-Lohmann, 2015). Currently, German dairy farmers produce more milk that meets the standards for pasture-raised milk than can be sold. This is attributable to the fact that about $40 \%$ of the dairy cows in Germany still have access to pasture (Destatis, 2010), whereas market shares for labeled pasture-raised milk remain low. However, especially for cooperative dairies, due to principles of equality, all farmers are entitled to bonus payments when adhering to a prescribed standard regardless of how their milk is sold. This can significantly force up remuneration payments. Total costs incurred are dependent on the individual structure of the dairies (Table 
Table 1. Cost factors and sales potential for pasture-raised milk based on the structure of dairies

\begin{tabular}{ll}
\hline Cost factor & Effect \\
$\begin{array}{l}\text { Segregation of raw materials } \\
\text { Separate collection }\end{array}$ & $\begin{array}{l}\text { Higher costs if farms meeting the criteria are regionally distributed and too small to fill } \\
\text { one transport unit }\end{array}$ \\
$\begin{array}{l}\text { Separate processing } \\
\text { Higher costs if no separate production line or factory exists, leading to conversion costs } \\
\text { Amount of total bonus payment for farmers }\end{array}$ & $\begin{array}{l}\text { Dependent on the percentage of dairy farmers meeting the criteria for pasture-raised } \\
\text { milk compared with the share of pasture-raised labeled products sold }\end{array}$ \\
\hline
\end{tabular}

1). As such, cost is the main reason why large dairies in Germany are not able to produce pasture-raised milk.

A higher market share of pasture-raised milk would reduce the bonus payments for milk that is not sold as pasture raised. However, pasture-raised milk is sold mainly as drinking milk, a segment that covers only a small percentage $(17 \%)$ of the milk processing chain in Germany (Milchindustrie, 2015).

To break the cycle of low quantities and high costs, dairies face 2 alternatives. The first is to expand the range of pasture-raised milk products by introducing new products, such as cheese. However, this is risky because consumers' willingness to pay (WTP) decreases with the degree of processing (Cicia and Colantuoni, 2010). Therefore, it could be even more difficult to cover the additional costs when selling processed "pasturebased" products. The second is to avoid segregation costs. This could be achieved by allowing the controlled mixing of pasture-raised milk with conventional barn milk.

For the marketing of mixed pasture-raised milk, alternative labeling concepts are needed. Two potential concepts are discussed in this article. One alternative resembles the mass balance approach, in which the minimum percentage of pasture-raised milk in the package is defined and claimed on the label. The other alternative follows the cause-related marketing approach, in which the label informs consumers that a purchase financially supports farmers who keep their cows on pasture.

Both strategies renounce the segregation of barn milk and pasture-raised milk, thereby increasing production efficiency for more dairies. This would facilitate the elevation of sustainable milk products from the current niche market. Price and availability barriers faced by consumers could thus be overcome (Jones et al., 2001). Thereby, more milk could be sold as pasture raised, making it easier to cover the farmers' bonus payments.

Results from previous choice experiments show that some consumer groups are willing to pay more for premium milk if the cows are kept in pasture-based husbandry systems (Tempesta and Vecchiato, 2013;
Wolf et al., 2011). Until now, only classic labels, which require the strict separate processing and marketing of conventional and premium milks along the milk supply chain (and thus are associated with higher costs), have been studied from a consumer's perspective. Therefore, the aim of this article is to analyze consumers' willingness to buy and pay for the classical and 2 alternative labeling strategies for pasture-raised milk. We conducted a choice experiment and linked it to a cluster analysis to account for existing consumer segments. The challenge is to find a viable marketing solution to protect pasturing of dairy cows as an important production process. To our best knowledge, this study is the first to compare 3 different labeling approaches for sustainable dairy husbandry.

\section{MATERIALS AND METHODS}

\section{Data Collection and Survey Design}

A total of 1,175 German milk consumers participated in a survey that sought input on their buying behavior and preferences for pasture-raised milk. An online access panel was used for data collection, and quotas were set for age, sex, income, and education to collect a sample that is approximately representative of the German population. The survey was conducted in January 2015. Participants who stated that they do not consume fresh milk were excluded from the survey sample before starting. After outliers were removed from the data set (Zhang and Conrad, 2014), a sample size of 1,065 was obtained. Furthermore, the survey included a test question to eliminate participants who read the questions only superficially; these participants were sorted out during data collection.

The survey started with sociodemographic questions. Afterward, participants were asked about their buying behavior for pasture-raised milk. In the next step, respondents were confronted with a discrete choice experiment in which they had to decide what milk they preferred to buy. Then, respondents were asked to evaluate the statements that built the foundation 
for the cluster analysis (statements are shown in Table 4). Respondents recorded their answers on a 5-point Likert scale ranging from 1 ("I do not agree at all") to 5 ("I totally agree"). All statements were randomized to avoid order effects (Schuman and Presser, 1981).

\section{Cluster Analysis}

The data were analyzed using IBM SPSS statistical software (version 23; IBM, Armonk, NY) to segment the respondents based on their response behavior to the statements asked. The statements were identified to separate the respondents and allow the cluster description to have a high level of meaning. These 9 statements (see Table 4) are related to relevant buying motives such as animal and environmental protection, which presents ethical interests that are gaining importance for food choice (Torjusen et al., 2001; Honkanen et al., 2006) and are relevant for buying pasture-raised milk, as pasturing is often associated with better welfare for dairy cows (Getter et al., 2014; Weinrich et al., 2014). Brand awareness and quality consciousness are also factors that influence the willingness to buy a food product (Carrigan and Attalla, 2001; Weatherell et al., 2003; Botonaki et al., 2006) and are important for our study because we use brand attributes in our choice experiment. In relation to milk, it is known that perceived product quality (e.g., health benefits) is also an influencing factor when buying animal-friendly milk (de Graaf et al., 2016). Furthermore, it is known that time pressure and price can act as barriers for consumers purchasing sustainably produced products (McEachern and Schröder, 2002; Grunert, 2005; Padel and Foster, 2005; Schulze and Spiller, 2008; Szmigin et al., 2009). Consideration of consumers' understanding of, and trust in, labels is important because this is one of the main criteria for the success of labeled products (Schröder and McEachern, 2004; Aertsens et al., 2009). Furthermore, the information search behavior was analyzed, as this is a further indicator of consumer involvement in food-buying decisions (Laurent and Kapferer, 1985).

The cluster analysis was executed by using a hierarchical cluster analysis with squared Euclidean distances as interval measure and the method of the nearest neighbor to identify outliers. Five respondents were removed by analyzing the dendrogram. After that, Ward's method was performed to identify the clusters. The correctness of assignment was examined by discriminant analysis. The mean values for the items for each cluster were computed by an ANOVA. The significance $(P \leq 0.05)$ of the differences between the clusters was determined with the Games-Howell post hoc test because the Levene test of homogeneity of variance was significant for all items. The obtained clusters were described by sociodemographic characteristics and the consumers' shopping behavior for pasture-raised milk.

\section{Choice Experiment}

We used a discrete choice experiment to assess consumer acceptance and preferences for the alternative labeling approaches. We created milk packages similar to the ones found on the German market to simulate a shopping situation. The presented milk packages differed with regard to 3 attributes (label, price, and brand) with either 2 or 4 levels (Table 2).

The price range used in the experiment was based on market prices for fresh milk identified in a store check before the survey. In Germany, consumers pay on average €0.59/L for milk in a discount store, €0.79/L for trademarks, €0.99/L for organic milk brands or trademarks, and €1.19/L for premium milk brands.

The 3 different labeling variants include the classical 100\% label and 2 alternatives. The first alternative included in our analysis is similar to the mass balance approach, which allows the mixing of sustainable and nonsustainable products. This is more cost effective, especially in the case of a low quantity of the certified product, which in our case is pasture-raised milk (Dehue et al., 2007). This kind of certification is already used in other industries such as the sustainable production of biomass (Dehue et al., 2007; Wangrakdiskul and Yodpijit, 2012; RSPO, 2016), wood (FSC, 2016), or fair trade orange juice and cocoa (Fairtrade, 2011). In some cases, provisions toward a minimum quantity exist so that a product is allowed to be labeled as sustainably produced only if this minimum is fulfilled (Goovaerts et

Table 2. Attributes for milk products in the choice experiment

\begin{tabular}{|c|c|c|c|c|}
\hline \multirow[b]{2}{*}{ Item } & \multicolumn{4}{|c|}{ Level } \\
\hline & $\begin{array}{l}\text { No } \\
\text { label }\end{array}$ & $\begin{array}{l}\text { Pasture-raised } \\
\text { milk } 100 \%\end{array}$ & $\begin{array}{l}\text { Pasture-raised } \\
\text { milk } 50 \% \text { mix }\end{array}$ & $\begin{array}{l}\text { Claim } \\
\text { label }^{1}\end{array}$ \\
\hline $\begin{array}{l}\text { Price }(€) \\
\text { Brand }\end{array}$ & $\begin{array}{c}0.59 \\
\text { Retailer brand }\end{array}$ & $\begin{array}{c}0.79 \\
\text { Manufacturer brand }\end{array}$ & 0.99 & 1.19 \\
\hline
\end{tabular}

${ }^{1}$ Included the claim "10 cents extra for farmers who keep their cows on pasture." 
al., 2013). An example of this is the Forest Stewardship Council (FSC) label. To use the "FSC Mix" label, a minimum share of $70 \%$ certified raw material is necessary (FSC, 2011). Introducing the mixed-label alternative allows more manufacturers to take part. This has a positive effect on the availability of the label on the market, and thus more publicity can be attained (FSC, 2016). In our case, we created a label that guarantees that the milk with this label contains at least $50 \%$ milk from cows with access to pasture. In the following, this label is named "50\%-mix label."

The second alternative labeling approach is oriented toward cause-related marketing. Cause-related marketing campaigns offer consumers the opportunity to support a particular cause when buying a product. Companies pay a part of their sales to a charitable or environmental activity, which is advertised on the product. The good cause is not necessarily related to the product, but in most cases at least some association exists between the product and the sustainability activity that is sponsored (Adkins, 2003). This kind of marketing shows high endorsement by consumers and can positively influence the image of a firm or an industry (Adkins, 2003). To generate a high level of trust, the amount of the donation has to be in good relation to the product price and should be mentioned objectively and in exact terms (Kim and Lee, 2009; Langen et al., 2010). Therefore, we decided to use the claim "10 cents extra for farmers who keep their cows on pasture" for a label using cause-related marketing for pasture-raised milk (named "claim label" in the following). We added the information that the additional amount is collected and distributed to all farmers keeping their cows on pasture. The main reason is to maintain a traditional husbandry system with pasture for dairy cows, which often is seen as more animal friendly (Armbrecht et al., 2015).

An unlabeled full factorial design was created in $\mathrm{R}$ (R Core Team, 2015) using the package support.CEs (Aizaki, 2012). The design, using 2 attributes with 4 levels each and 1 attribute with 2 levels, yields 32 $\left(4^{2} \times 2^{1}\right)$ possible profiles. These 32 -choice sets were partitioned into 8 blocks to reduce the burden placed on the individual participant and to prevent fatigue. Thus, each participant was asked to choose 1 of 2 milk packages 4 times. Participants also had the option to choose none of the presented milk packages. Respondents were randomly assigned to 1 of the 8 blocks, and the individual choice tasks were randomized to avoid order and learning effects. A sample choice situation is presented in Figure 1.

We estimated a random parameter logit (RPL) model using the $\mathrm{R}$ package mlogit (Croissant, 2013) to analyze the choice behavior of the respondents. The
RPL model is based on random coefficients. The utility $U$ derived by person $n$ from choosing alternative $j$ from the full choice set is specified as a linear additive in parameters

$$
U_{n j}=\boldsymbol{\beta}_{n}^{\prime} x_{n j}+\varepsilon_{n j},
$$

where $x_{n j}$ represents the characteristics of the alternative choices faced by the decision maker, $\boldsymbol{\beta}_{n}^{\prime}$ is the coefficients representing person $n$ 's taste, and $\varepsilon_{n j}$ is a random error term that is extreme-value distributed. In contrast to the multinomial logit model, the taste parameters are not considered fixed among decision makers in the RPL model but rather are assumed to be multivariate normally $(M V N)$ distributed, such that

$$
\boldsymbol{\beta}_{n}=\overline{\boldsymbol{\beta}}+\tau_{n}, \tau_{n} \sim \operatorname{MVN}(0, \boldsymbol{\Omega}) .
$$

Following this specification, individual tastes are assumed to be drawn from this distribution, where $\beta$ is the mean taste vector for the sample and $\Omega$ is the covariance matrix of the taste distribution (Swait, 2006; Train, 2009).

The probability density of $\boldsymbol{\beta}$ for the introduced labeling alternatives was assumed to follow a normal distribution. We report 2 RPL models: a total sample solution (Model 1) and a cluster solution (Model 2), which accounts for higher order differences in preferences and includes interaction terms between attribute levels and the cluster information. Taking the panel structure of our data into account, the utility function used in the estimation of Model 2 allowed for heterogeneity across consumer segments and is specified as a linear additive in parameters as follows:

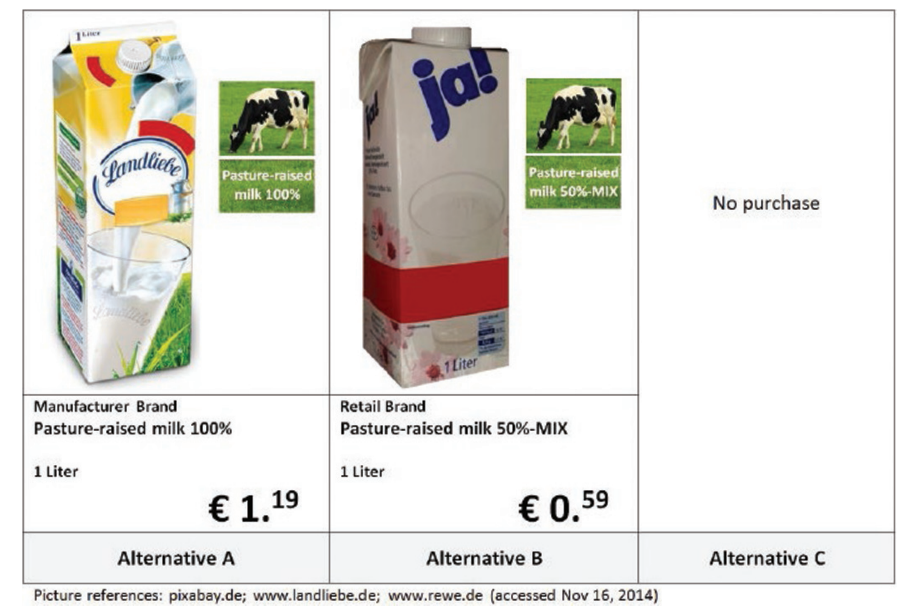

Figure 1. Sample choice set. Color version available online. 


$$
\begin{aligned}
U_{i j t \mid q} & =\boldsymbol{\beta}_{\mathrm{ASC} \mid q} \mathrm{ASC}_{i j t}+\boldsymbol{\beta}_{\text {price|q}} \text { price }_{i j t}+\boldsymbol{\beta}_{\text {label } \mid q} \text { label }_{i j t} \\
& +\boldsymbol{\beta}_{\text {brand } \mid q} \text { brand }_{i j t}+\varepsilon_{i j t \mid q},
\end{aligned}
$$

where $U_{i j t q}$ represents the utility an individual $i$ belonging to cluster $q$ (see Table 4 for cluster information) derives from alternative $j$ in choice situation $t$. The alternative specific constant (ASC) reflects a dummycoded constant for choosing instead of not choosing a product. The label and brand attributes entered the utility specification as dummy-coded variables, whereas price was modeled as a continuous variable. We used model specification tests (i.e., likelihood ratio test, Wald test, and Score test as implemented in the mlogit package) to justify our model structure and the choice of random parameters. Price was incorporated as a fixed coefficient to ease subsequent WTP calculations. Tests for random parameters among the ASC, labeling, and brand attributes rejected the hypothesis of random coefficients for the $50 \%$ label. The ASC, brand, and labeling attributes where thus included as random parameters following a normal distribution. To account for the fact that repeated choice observations were drawn from the same individuals, random parameters are allowed to correlate, which reflects the behavioral principle that an individual uses the same preferences to evaluate different choice situations (Hensher and Greene, 2003).

Mean WTP for a certain product characteristic (e.g., the claim label) was then computed as the ratio between the estimated coefficients of the sample mean (Model 1) and cluster means (Model 2) for the product characteristic and price (Louviere et al., 2000):

$$
\mathrm{WTP}_{\text {label }}=-\boldsymbol{\beta}_{\text {label }}^{\prime} / \boldsymbol{\beta}_{\text {price }}^{\prime} \text {. }
$$

\section{Qualitative Evaluation of Associations With Mass Balance Certification}

Consumers' attitudes toward mass balance certification remain largely unexplored. Only 1 study by Batte et al. (2007) analyzed consumers' WTP for organic labels for processed food containing a minimum percentage $(70 \%)$ of organically produced ingredients. The results give first hints that consumers accept mixed labels, although the WTP is lower than that for $100 \%$ organic food.

However, knowledge about consumer attitudes is still low, especially with regard to consumers' acceptance of mixed labels for nonprocessed food, such as pastureraised milk. Therefore, we asked respondents to note 3 thoughts that spontaneously came to mind when being introduced to this alternative labeling. Before they wrote down their thoughts, we provided them with brief information about the mixing of conventional milk and milk produced by cows with access to pasture at least $120 \mathrm{~d} / \mathrm{yr}$ and $6 \mathrm{~h} / \mathrm{d}$. Respondents were not informed about the reasons for and advantages of mixing because consumers who will buy this kind of milk in the supermarket will most likely be uninformed in the beginning. Thus, we wanted to analyze the respondents' unaffected associations and opinions.

The respondents' first associations were analyzed using content-related structural data analysis. Due to the large volume of data, the analysis was conducted using QDA software (MAXQDA, 2016). We used a combination of deductive analysis and inductive analysis. Thus, first we determined whether the categories were positive, neutral, or negative and created additional subcategories for a better understanding of why the approach was evaluated as positive, neutral, or negative (Thomas, 2006). Two people assigned the answers to the categories independently of each other. Deviations were discussed with a third person to guarantee a replicable result. The evaluation was done with the software MAX QDA 12.

\section{RESULTS}

\section{Sample Description}

The sampling distribution is shown in Table 3. It can be seen that the sample is less educated than the German population. The sample is similar to the distribution in Germany in terms of sex and age. However, with an average age of $49.3 \mathrm{yr}$ ( minimum $=17 \mathrm{yr}$; maximum $=86 \mathrm{yr}$ ), our sample is slightly older than the German population (Statista, 2016). The income distribution within the sample deviates from the census data: Respondents with higher incomes (net household income $>€ 3,500)$ are underrepresented, whereas individuals from middle income brackets are overrepresented. Just over one half of the participants buy milk (very) often. Nonbuyers of milk were eliminated from the analyzed sample.

\section{Cluster Analysis}

As the results of the cluster analysis are also relevant for the interpretation of the discrete choice experiment, the results are shown first. Overall, we identified 4 clusters based on 9 statements (Table 4). The clusters are further described by sociodemographic factors and the frequency with which consumers purchase pastureraised milk to identify the relevance of the clusters for this market. 
The first cluster, cluster A, is the smallest one (15.1\%) and is named "quality-conscious and ethically involved consumers," as this group has the highest agreement with the statement "I would describe myself as very quality conscious when buying food" (mean $=4.23 ; P$ $<0.5)$. This cluster also has the highest mean values for the statements "The welfare of farm animals is important to me" (mean $=4.78 ; P<0.5)$ and "Environmental and nature protection are important issues for me" $($ mean $=4.78 ; P<0.5)$. Both of these statements emphasize the consumers' interest and involvement in animal welfare and nature conservation. Their food involvement is underlined by their strong rejection of the statement "For me, shopping has to be fast" (mean = $2.30 ; P<0.5)$ and the highest agreement with "I take my time to inform myself about the products I buy" (mean $=3.88 ; P<0.5)$. In addition to these ethical aspects, this group is willing to pay more for brands and is less price sensitive (compared with clusters C and $\mathrm{D} ; P<0.5)$. Furthermore, this group includes more buyers of pasture-raised milk than the other clusters: $57.9 \%$ said that they buy pasture-raised milk often or at least sometimes. Additionally, this group evaluates the influence of pasturing on milk quality and taste significantly more positively than the other clusters $(P$ $<0.5)$.

The second cluster, cluster B, includes $16.9 \%$ of the respondents. This group shows a lower concern for the welfare of farm animals and environmental protection (compared with clusters $\mathrm{A}$ and $\mathrm{C}$; mean $=3.79 ; P<$ 0.5 ) but a high interest in branded products (compared

Table 3. Sample description $(\mathrm{N}=1,065)$

\begin{tabular}{lcc}
\hline Item & $\begin{array}{c}\text { Sample } \\
(\%)\end{array}$ & $\begin{array}{c}\text { German } \\
\text { population } \\
(\%)\end{array}$ \\
\hline Sex ${ }^{1}$ & & \\
$\quad$ Male & 47.9 & 49.0 \\
Female & 52.1 & 51.0 \\
Age $^{2}(\mathrm{yr})$ & & \\
$\quad 16-29$ & 18.6 & 18.9 \\
$30-49$ & 32.2 & 31.7 \\
$>50$ & 49.2 & 49.4 \\
Income $^{3}(€ / \mathrm{mo})$ & & \\
$<1,500$ & 24.1 & 23.2 \\
1,500 to $<2,500^{4}$ & 37.9 & 27.6 \\
2,500 to $<3,500^{5}$ & 23.0 & 17.6 \\
$>3,500$ & 15.0 & 31.6 \\
Education & & \\
Lower secondary & 41.6 & 33.9 \\
Middle school & 37.5 & 29.8 \\
High school & 20.3 & 28.9 \\
\hline
\end{tabular}

${ }^{1}$ Statistisches Bundesamt (2015b).

${ }^{2}$ Statista (2016).

${ }^{3}$ Statistisches Bundesamt (2015a).

${ }^{4} \mathrm{Up}$ to 2,600 in the German population.

${ }^{5} \mathrm{Up}$ to 3,600 in the German population. with clusters $\mathrm{C}$ and $\mathrm{D}$; mean $=4.01 ; P<0.5)$. They also trust labels and take less time for shopping. They are named "proponents of labels and brands," as these aspects are most characterizing for them compared with their other evaluations. Additionally, this group involves fewer consumers with a low income $(<€ 1,500 /$ mo), and consumers of this group buy pasture-raised milk at above-average frequency $(42.7 \%)$. Because individuals with incomes above $€ 3,500 /$ mo are more likely to belong to this cluster and because this income group is underrepresented in our sample, it can be assumed that this cluster is potentially larger among the actual population than is reflected in the present study.

The biggest cluster $(41.3 \%)$, cluster C, is called "involved buyers under time and price pressure." This cluster includes consumers who are also highly involved in animal and environmental protection but less than those in cluster $\mathrm{A}$ (mean $=4.27 ; P<0.5)$. This group is further characterized by their high agreement with the statement "For me, shopping has to be fast" (mean $=3.33 ; P<0.5)$. The respondents in this group are less quality conscious than those in clusters $\mathrm{A}$ and $\mathrm{B}$ (mean $=3.50 ; P<0.5)$ and more price sensitive (mean $=$ 3.38; $P<0.5)$. Brand-name products and labels are less important to them because their trust in labels is low. Regarding their sociodemographic profile, this group is similar to the sample average.

The last cluster, cluster $\mathrm{D}$, is named "price sensitives" $(26.7 \%)$. The respondents in this cluster show the highest agreement with the statement "I first pay attention to the price when I buy food" (mean $=3.90 ; P$ $<0.5$ ) and are less interested in animal welfare, nature conservation, and quality and branded products. This group also does not have much time for shopping or for reading product information. Consumers combined in this cluster are more represented in the group with the lowest income; their purchasing frequency of pastureraised milk is below average $(14.5 \%)$.

\section{RPL Model}

The parameter estimates of the RPL model for fixed and random effects for the total sample population (Model 1) are listed in Table 5. Table 5 shows the partworth utilities for 3 attributes: price, brand, and label. As expected, the coefficient for price is negative. This shows that milk consumers are price sensitive, and a higher price negatively influences the perceived utility of a shown product. Regarding the brand attribute, it can be concluded that the presence of a manufacturer's brand significantly increased the probability of a product being chosen. Considering the different labeling approaches, the consumers received the highest utility from the traditional 100\% label. This was closely 
KÜHL ET AL.

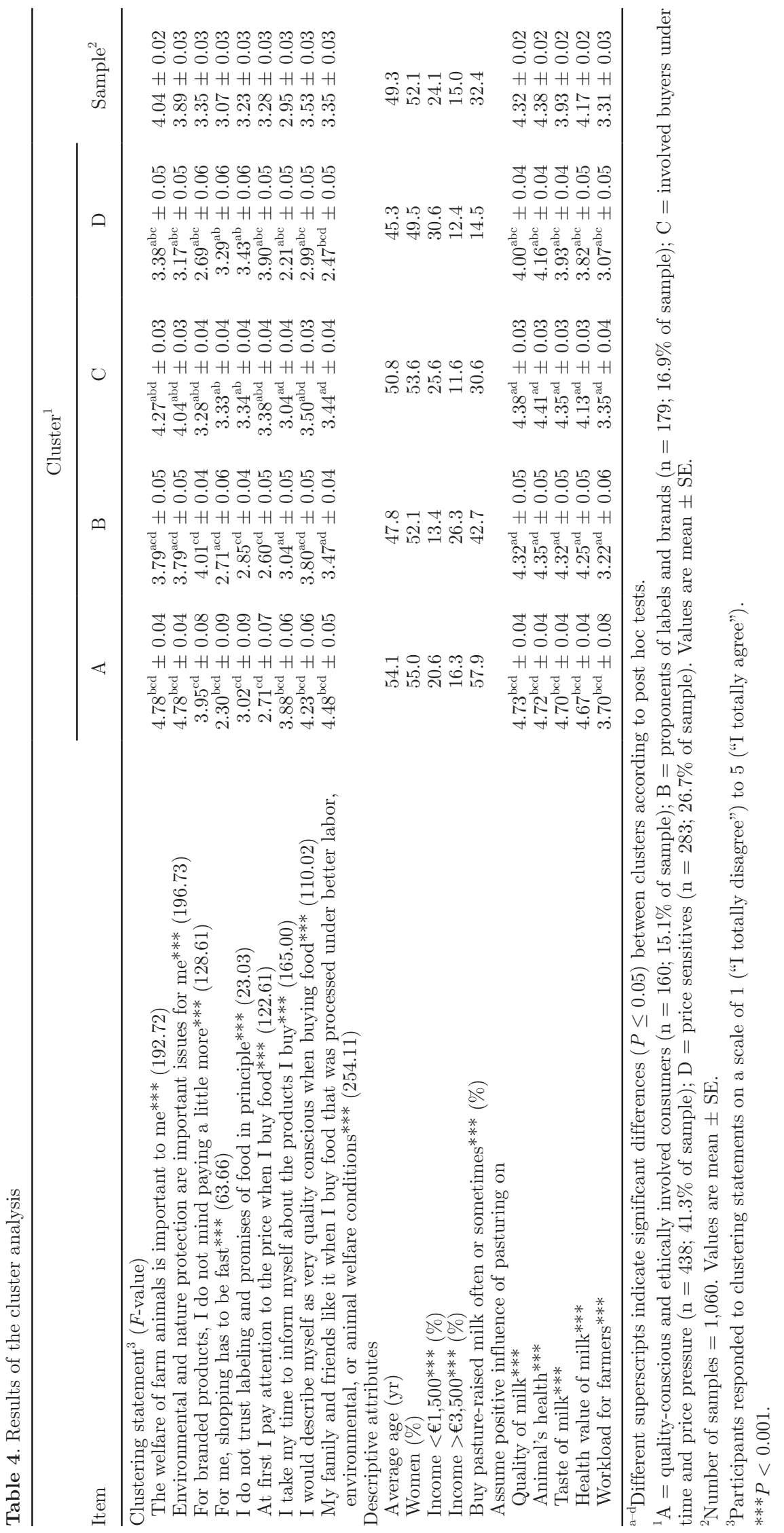


followed by the cause-related marketing claim (claim label). The mass balance claim (50\%-mix label) was significantly less preferred, although 50\%-mix labeled products were valued significantly more positively than products without any claim. The estimated standard deviations for the $100 \%$ label and the claim label as well as the brand information are significantly different from zero, suggesting that heterogeneity exists with respect to the valuation of these attributes among the surveyed population.

Table 5 also shows the RPL model estimation results for the different target groups (Model 2) as described in the cluster analysis (Table 4). Cluster A (quality-conscious and ethically involved consumers) receives the highest utility from buying a milk package with 1 of the 3 labels but prefers the 100\% label. Price has the lowest negative influence for this cluster. Cluster B (proponents of labels and brands) shows the highest utility for the brand and has average values for the labels and the price. The biggest cluster, cluster $\mathrm{C}$ (involved buyers under time pressure), derives less utility when buying labels but, like all the other clusters, prefers the $100 \%$ label. Brand has a low influence on cluster $\mathrm{C}$, whereas this cluster is more influenced by price than are clusters $\mathrm{A}$ and B. The last cluster, cluster D (price sensitive), shows a highly negative reaction to a high price, and the values for brand or the labels are lowest.

\section{Additional WTP}

Next to the estimation of the model coefficients, WTP values for the different labels were calculated by applying Equation 4. The values presented in Table 6 reflect the amount that the average respondent in the total sample (Model 1) and the average respondents among each individual consumer segment (Model 2) is willing to pay for a certain product characteristic. Estimates need to be interpreted carefully because of the hypothetical nature of the present study. Because those surveyed made no monetary payments, WTP could be overestimated (see, e.g., Lusk and Schröder, 2004). Nevertheless, a trend can be identified from the results by putting the different labels in relation to each other.

Looking at the WTP values, it becomes evident from the total sample model that the classical labeling approach (more specifically, product segregation ensuring a $100 \%$ certified pasture-raised milk content in a milk package) can claim the highest premium of $€ 0.50$ compared with conventional, nonlabeled milk. However, this is closely followed by the cause-related claim (claim label) of redistributing 10 cents per package sold to farmers who keep their cows on pastures. Respondents were on average willing to pay up to $€ 0.38$ more for milk with this claim compared with conventionally pro- duced milk. Pasture-raised milk certified according to the mass balance approach could claim a premium of $€ 0.12$ among the surveyed consumers. However, WTP values derived from the cluster solution model show large heterogeneity among different consumer groups. Still, respondents across segments were willing to pay relatively more for the classical label compared with all other labeling alternatives. The results for cluster A-relatively low price sensitivity paired with a pronounced interest in the welfare of farm animals particularly stand out. Although the reported WTP values seem unreasonably high, they are an expression of this strong preference of ethical issues over price. It is evident from the cluster solution that mass balancing would generate premiums not among price-sensitive consumers but rather among ethically involved consumers. However, about two thirds of the sample show potential for pasture-raised milk purchases because both the classical and claim labels generate price premiums. A claim label could increase overall market shares of pasture-raised milk due to lower production costs and the potentially lower price premiums needed to satisfy production costs, including farmer bonuses.

\section{Results of Open Associations to Mass Balance Certification}

To gain insight into consumers' attitudes toward and their understanding of mass balance certification, we used open-ended questions. Of the respondents, 931 wrote down at least one thought related to the subject of mass balance certification. To ensure that we analyzed only thoughts that truly were related to mass balance certification, we excluded all answers that expressed more general concerns such as the welfare of animals in husbandry systems or the role of prices during food purchase. Finally, 569 respondents' thoughts were included in the evaluation. Because no striking differences were found between the clusters, we show all answers for the whole sample.

Table 7 shows an overview of the 3 main categories and their subcategories. The percentage of the subcategories refers to the total number of statements within the main category.

Looking at the main categories, it can be seen that most thoughts were negative $(60.98 \% ; \mathrm{n}=347)$, whereas only $24.08 \%(\mathrm{n}=137)$ of the mentioned associations were seen as positive and $14.94 \%(\mathrm{n}=85)$ were neutral. Looking more closely at the negative thoughts revealed that, next to general statements (e.g., "I do not like this"), which were summarized in the subcategory "general statements against mixing," skepticism about whether the promised criteria would actually be met $(19.60 \%)$ is one of the main criticisms consumers have. 
KÜHL ET AL.

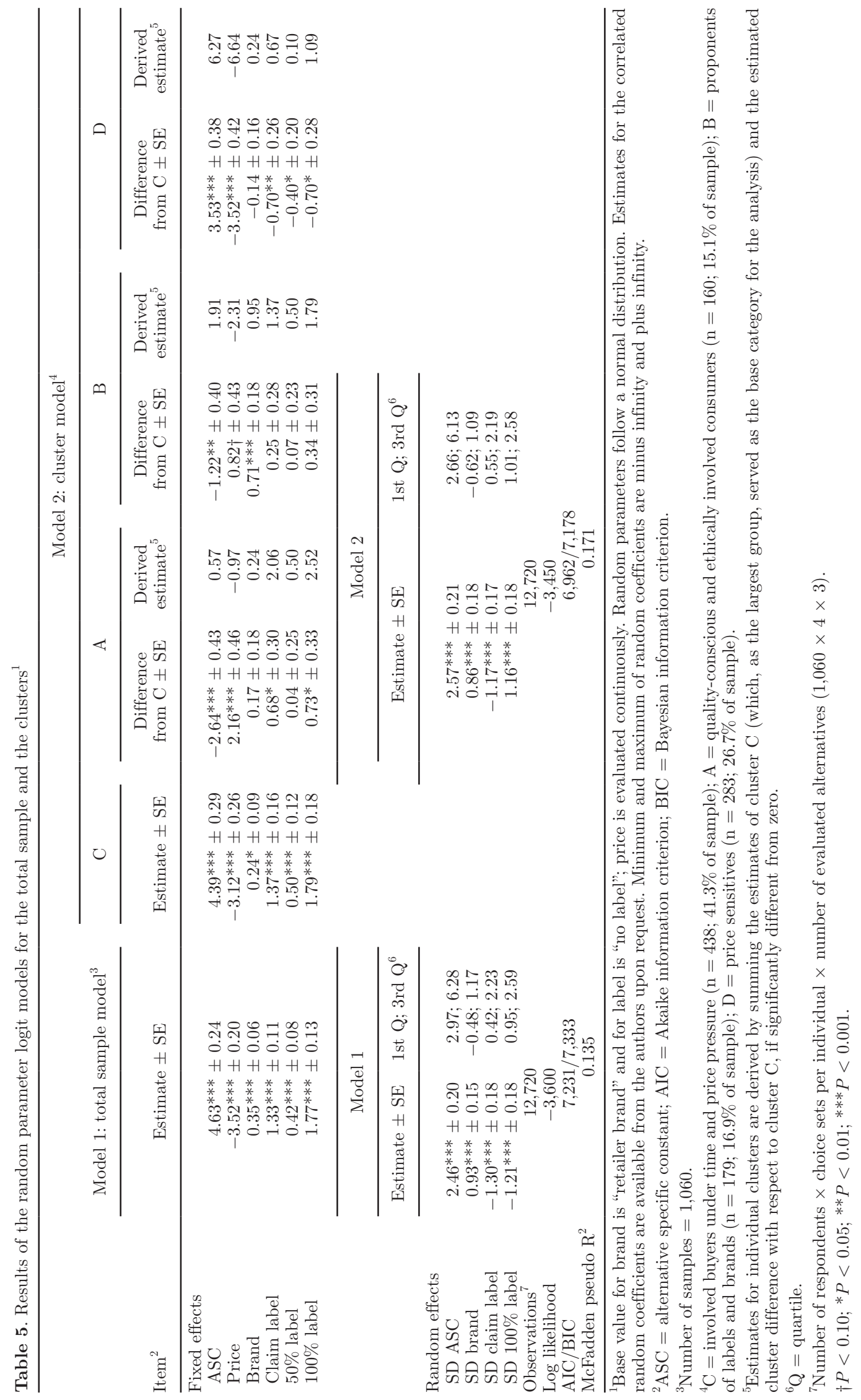


Table 6. Price premiums $(€ / L)$ paid by the average individual in the total sample and the individual consumer segments relative to a package of conventional milk or a retailer brand

\begin{tabular}{lcccccc}
\hline & Model 1 & \multicolumn{5}{c}{ Model 2 } \\
\cline { 2 - 6 } \cline { 5 - 7 } Item & Total sample & & $\mathrm{A}$ & $\mathrm{B}$ & $\mathrm{C}$ & $\mathrm{D}$ \\
\hline Claim label & 0.38 & & 2.12 & 0.59 & 0.44 & 0.10 \\
50\% label & 0.12 & & 0.52 & 0.22 & 0.16 & 0.02 \\
100\% label & 0.50 & & 2.60 & 0.78 & 0.57 & 0.16 \\
Brand & 0.10 & & 0.24 & 0.41 & 0.08 & 0.04 \\
\hline
\end{tabular}

${ }^{1} \mathrm{~A}=$ quality-conscious and ethically involved consumers $(\mathrm{n}=160 ; 15.1 \%$ of sample); $\mathrm{B}=$ proponents of labels and brands ( $\mathrm{n}=179 ; 16.9 \%$ of sample); $\mathrm{C}=$ involved buyers under time and price pressure $(\mathrm{n}=438 ; 41.3 \%$ of sample); $\mathrm{D}=$ price sensitives $(\mathrm{n}=283 ; 26.7 \%$ of sample).

Furthermore, $13.54 \%$ see this kind of labeling as either misleading or deceptive. Some statements that were given repeatedly were "I do not believe it," "Mixing is not trustworthy," "How is this going to be controlled," and "This is deception of consumers." Some respondents do not understand how this kind of labeling will be put into practice $(6.34 \%)$, and others mention transparency and traceability issues (7.20\%). Respondents also made statements related to more egoistical factors such as taste and health value, which is lower if pasture-raised milk is mixed with conventional milk; this is mentioned less often $(2.59 \%)$.

Respondents who evaluated the approach of mixing positively mostly see the advantages of such a concept. They argue that such a certification approach can be seen as a first step toward ensuring farm animal welfare and that this is better than doing nothing at all (12.41\%). Some respondents (10.95\%) also state the advantages that come with lower prices; thus, more consumers will be both able and willing to buy the certified product. Statements include "Due to the lower price more consumers are willing to buy the product" and "A good combination of saved costs and buying consciously." Moreover, respondents also see a fairness aspect $(9.49 \%)$ and mention the enhanced welfare of farm animals $(8.03 \%)$.

Furthermore, we summarized all statements under the neutral category that are neither negative nor positive. This includes statements such as "At least you are supporting something good at 50\%, although $100 \%$ would be better" and "Sounds interesting, but I am skeptical."

\section{DISCUSSION}

The access of cows to pasture is a controversial discussion in dairy science with respect to the well-being and health of the animals on one hand and economic aspects such as milk yield and productivity on the other (e.g., White et al., 2002; Hernandez-Mendo et al., 2007; Bergsten et al., 2015; Schären et al., 2016). However, pasturing influences the societal perception of the dairy industry positively and reduces existing concerns about dairy farming (Cardoso et al., 2016;

Table 7. Categories and subcategories of respondents' stated associations with mass balance certification (50\% label)

\begin{tabular}{lrcc}
\hline Category & $\begin{array}{c}\text { Total } \\
\text { no. }\end{array}$ & $\begin{array}{c}\text { Percentage } \\
\text { of the main } \\
\text { category }\end{array}$ & $\begin{array}{c}\text { Percentage } \\
\text { of all statements } \\
(\mathrm{n}=569)\end{array}$ \\
\hline Main category: negative & 347 & & 60.98 \\
General statements & 171 & 49.28 & 30.05 \\
Distrust/skepticism & 68 & 19.60 & 11.95 \\
Fraud/consumer deception & 47 & 13.54 & 8.26 \\
No transparency & 25 & 7.20 & 4.39 \\
Lack of understanding/confusion & 22 & 6.34 & 1.58 \\
Bad taste/low health value & 9 & 2.59 & 0.88 \\
Unfair & 5 & 1.44 & 24.08 \\
Main category: positive & 137 & 59.12 & 2.99 \\
General statements & 81 & 12.41 & 2.63 \\
Better than nothing & 17 & 10.95 & 2.28 \\
Cheaper and better & 15 & 9.49 & 1.93 \\
Fair & 13 & 8.03 & 14.94 \\
Enhanced welfare for farm animals & 11 & & \\
Neutral & 85 & & \\
\hline
\end{tabular}


Wolf et al., 2016). It is forecasted that the percentage of pasturing for dairy cows is declining in some European countries and the United States (Reijs et al., 2013; Nehring et al., 2016). Thus, marketing pasture-raised milk is an issue in these countries to maintain pasturing by creating a higher value from this milk. However, the marketing of pasture-raised milk often leads to typical niche-market problems because of the necessity of segregating conventional from quality-enhanced commodities (Giannakas, 2002; McEachern and Schröder, 2002; Dehue et al., 2007). This means that small quantities often result in higher production costs and therefore elevated consumer prices, which in return keep sales small because price is a main barrier when buying sustainable food (McEachern and Schröder, 2002). Thus, with a high consumer price, little pasture-raised milk is sold and therefore only few farmers would be able to receive bonus payments as an incentive to keep pasturing their dairy cows. One possibility for reducing costs and avoiding this cycle is the avoidance of segregation and thereby the lowering of production costs without decreasing the bonus payments for farmers. Therefore, we tested 2 new types of labeling that do not require product separation.

The results of the choice experiment show that the $100 \%$ label is most interesting and favorable for consumers when buying pasture-raised milk. This seems obvious as consumers are familiar with this kind of labeling and because it is easier to understand (Weinrich et al., 2015). We furthermore found the highest WTP for the classical label compared with the 2 alternatives. Our WTP results are similar to what was found by Weinrich et al. (2014). However, the cause-related approach was also highly accepted and deemed useful by consumers. The 50\%-mix label seemed to be less beneficial for them. The value attributed to the mass balance approach was significantly lower for all consumer segments compared with the other 2 labeling alternatives. This is surprising; it seems more likely that consumers have a higher preference for this kind of labeling because it guarantees that at least half of the comprised milk is produced by cows with access to pastures, whereas consumers do not know the percentage of pasture-raised milk in the cause-related approach. However, one reason could be that the mass balance approach is too complicated. Hints toward this conclusion are given by Weinrich et al. (2015), who found that trust is low in labels that are too complex, and trust is an important influencing factor in buying decisions (Aertsens et al., 2009). Our analysis of the openly stated associations with mass balancing underlines this finding, as most consumers seem to have mainly negative associations when they are introduced to the mixing of pasture-raised milk with conventional milk. Distrust and skepticism are the main reasons for the rejection of the mixed label. Furthermore, consumers see transparency and traceability of milk products as critical. Charlebois and Haratifar (2015) also showed that traceability is an important aspect for consumers in their buying decisions for milk products.

However, a study by Batte et al. (2007) showed that consumers are willing to pay more for organic processed food containing between 70 and $95 \%$ organic ingredients. An explanation could be that the authors used an established organic label for their survey. Maybe, if trust is given, mixed labels can be seen as more beneficial. However, for our study we can conclude that the mixed-label approach does not seem very promising when used for pasture-raised milk. An assumption could be that the percentage of pasture-raised milk contained in a milk package is a reason for the missing acceptance, but no respondent mentioned that the percentage is too low. In fact, the criticism is more general.

These problems seem to be overcome by the concept of cause-related marketing. It is already known from the literature that this approach is evaluated positively by consumers (Adkins, 2003), especially if the supported cause is important to them (Sheikh and Beise-Zee, 2011). As the welfare of farm animals is very important for most consumers and because consumers associate pasture with enhanced farm animal welfare (McEachern and Schröder, 2002; Schuppli et al., 2014; Weinrich et al., 2014), it seems obvious that supporting pasturing would be a highly important cause for consumers. This explains the high WTP for milk that claims to support pasturing for dairy cows. In addition, consumers' desires for more transparency and a fair payment for farmers are better satisfied by this concept (Busch and Spiller, 2016).

To get a better understanding of which consumer segments are willing to buy pasture-raised milk and positively react to the 2 labeling alternatives, we added a cluster analysis. We examined 2 main target groups for pasture-raised milk that make up about $30 \%$ of all consumers. This percentage of buyers of premium milk is consistent with figures that revealed that about $30 \%$ of the drinking milk sold in Germany from October 2014 to September 2015 was sold at a higher price because it was either premium milk (typically high-priced brands) or organic milk (Els, 2015). Therefore, we can conclude that our segmentation approximately reflects the actual consumer segments for milk in Germany. We furthermore found a bigger group of interested but more pricesensitive consumers (cluster C; 41.3\%) and 1 group of consumers who are less interested and therefore not relevant as buyers of pasture-raised milk (cluster D; $26.7 \%$ ). A disinterested consumer group such as cluster D often can be found when doing consumer segmen- 
tation (see, e.g., Heerwagen et al., 2015). In our case this group is most price sensitive and is not interested in pasture-raised milk or in ethical aspects in general. Therefore, this group cannot be seen as a target group; this could also be influenced by their lower income.

A closer look at the different consumer segments shows that especially cluster A (quality-conscious and ethically involved consumers; $15.1 \%$ ) can be seen as a main target group for pasture-raised milk. The RPL model highlights that this group receives the highest benefit from buying pasture-raised milk with either the $100 \%$ label or the cause-related claim. In combination with their relatively lower price sensitivity, this group has the highest WTP for these labels. Thus, the results are in line with findings by Laroche et al. (2001) stating that consumers with a higher interest in ethical aspects are willing to pay more. In the case of pasture-raised milk, it can be assumed that the animal friendliness of the husbandry system including pasturing is one main aspect. Animal welfare is an important topic for society, and consumers often evaluate pasturing as positive for the welfare of animals (McEachern and Schröder, 2002; Schuppli et al., 2014; Weinrich et al., 2014). However, animal friendliness is also associated with better taste and health value of milk (de Graaf et al., 2016), which are also motives for buying pasture-raised milk. Consumers in cluster A show the highest expectations toward pasture-raised milk in all these aspects: They assume that the milk tastes better and has a higher health value and expect that the cows are healthier. Therefore, we can conclude that this group is the main target group for the $100 \%$ label, as they are willing to pay more and expect more egoistical motives such as taste and quality, both of which are given only if milk is actually produced by cows grazing on pasture.

Cluster B (proponents of labels and brands; 16.9\%) is another interesting target group for premium food products. This group is very interested in labels and brands and is less price sensitive. The results of the RPL model confirm that this group receives the highest utility from buying a branded product but shows a lower WTP for products with a label for pasture-raised milk compared with cluster A. In contrast to cluster A, cluster B shows lower interest in ethical topics, such as animal welfare and nature protection. Yet, at the same time, the cluster members are highly interested in labels and brands. We further know that participants in cluster B agree more with the statement "For me, shopping has to be fast" compared with cluster A and take less time to inform themselves about products. Consequently, it can be concluded that these consumers use brands and labels as orientation for their food purchase and thus do not bother reading information presented on food packaging. This consumer segment could be an interesting target group for pasture-raised milk offered in combination with a brand name, but a trustful label could also appeal to them. The $100 \%$ label is preferred by this group, which seems obvious as they are less interested in ethical aspects that are supported mainly by the mass balance approach and cause-related marketing.

Cluster C (involved buyers under time pressure) is similar to cluster $\mathrm{B}$ with respect to their sense of time pressure. However, compared with cluster B, this group is more price sensitive. Along with their lower perceived benefit of brands, it can be assumed that these consumers have a lower propensity to pay more for branded products. At the same time, this group is more interested in topics such as the welfare of farm animals and nature protection compared with cluster B (but not as much as cluster A). Therefore, labels could be a good solution for this group because they inform consumers about animal welfare without requiring consumers to put significant thought into their purchases. However, to reach this group labels have to be clear, easy to understand, and, due to this group's lack of trust in labels, credible. Furthermore, this group pays more attention to the price, which is known as one main barrier for purchasing sustainable food (McEachern and Schröder, 2002; Padel and Foster, 2005). Therefore, this group may be more interested in labeled products at lower prices. This could call for the mass balance approach. The concept of mere mass balance certification is not understood by everyone and is seen with distrust and skepticism by the majority of respondents; therefore, cause-related marketing would be the better alternative. These consumers could still support animal welfare and health, as this is the most important aspect for them, when buying pasture-raised milk for a comparatively lower price. However, the aim of the cause-related marketing approach is to sell more pasture-raised milk because of a more favorable retail price without lowering the bonus payment for farmers pasturing their cows. These bonuses are necessary to motivate farmers to continue keeping their cows on pasture. Cause-related marketing could support the pasturing of dairy cows because costs can be saved by mixing the commodities rather than by reducing the bonus payments for farmers.

Our results must be seen as a first indication of consumers' willingness to buy and pay for the 2 alternative labeling strategies introduced in the choice experiment because the simulated purchasing scenario was hypothetical and was restricted to not reflect the current retail environment. Notably, we did not include organic milk in the experiment. However, its presence could 
influence consumers' buying and trade-off decisions between different labeling approaches or even between pasture-raised and organic milk. Furthermore, it would be interesting to know how the introduced alternative labeling strategies are accepted when used for processed milk products such as cheese or yogurt, as this would also be important for increasing the market share of pasture-raised milk.

\section{CONCLUSIONS}

It can be concluded that dairies that would like to produce sustainable milk products such as pastureraised milk face 2 possibilities. The first is to market premium milk with a $100 \%$ label and thus segregate the milk from their conventional (barn) milk during collection and processing. Due to higher costs, this kind of labeling is especially interesting for dairies, which are more oriented toward market differentiation and therefore have the ability to produce separately. Consumers who are less price sensitive can be seen as main target groups, whereas it could be advantageous to combine the label with a brand because some consumers show higher WTP depending on whether the milk is branded. The second option is cause-related marketing. This kind of labeling can help such products leave the niche market and be consumed by a large share of involved yet more price-sensitive consumers. However, cause-related marketing is not most beneficial for all consumers. Some consumers buy pasture-raised milk on the assumption of better taste and higher health value. Therefore, besides the traditional labeling approach that relies on the costly segregation of barn- and pasture-raised producing dairy cows, we recommend using cause-related marketing as an approach for targeting more cost-oriented producers and price-sensitive consumers with mainly altruistic buying motives. Considering the positive evaluation of the cause-related marketing concept, this marketing strategy seems to be underdeveloped in food labeling in general and in the dairy market. Further research and consideration seems necessary, especially because it provides a possibility to market sustainable products at a lower consumer price by reducing costs without reducing bonus payments for farmers.

\section{ACKNOWLEDGMENTS}

The study was supported by the Ministry for Science and Culture of Lower Saxony (Hannover, Germany) within the collaborative research project SAM, Analysis of Dairy Production: Grazing Versus Indoor Housing of Dairy Cows (support code ZN 2864).

\section{REFERENCES}

Adkins, S. 2003. Cause-related marketing: Who cares wins. Pages 669 693 in The Marketing Book. 5th ed. M. J. Baker, ed. ButterworthHeinemann, Oxford, UK.

Aertsens, J., W. Verbeke, K. Mondelaers, and G. Van Huylenbroeck. 2009. Personal determinants of organic food consumption: A review. Br. Food J. 111:1140-1167. https://doi. org/10.1108/00070700910992961.

Aizaki, H. 2012. Basic functions for supporting an implementation of choice experiments in R. J. Stat. Software 50:1-24.

Els, T. 2015. Verbraucher zwischen Anspruch und Realität. Presentation at Themenforum Weidemilch, Aurich, Germany. Gründlandzentrum, Ovelgönne, Germany.

Armbrecht, L., C. Lambertz, D. Albers, and M. Gauly. 2015. Tierwohl von Milchkühen bei Stall- und Weidehaltung-Ein Vergleich anhand des Welfare Quality Protokolls. Pages 70-73 in Conference Proceedings Tierwohl-Tagung 2015, Georg-August-University, Göttingen, Germany.

Batte, M., N. H. Hooker, T. C. Haab, and J. Beaverson. 2007. Putting their money where their mouths are: Consumer willingness to pay for multi-ingredient, processed organic food products. Food Policy 32:145-159. https://doi.org/10.1016/j.foodpol.2006.05.003.

Bergsten, C., J. Carlsson, and M. Jansson Mörk. 2015. Influence of grazing management on claw disorders in Swedish freestall dairies with mandatory grazing. J. Dairy Sci. 98:6151-6162. https://doi. org/10.3168/jds.2014-9237.

Botonaki, A., K. Polymeros, E. Tsakiridou, and K. Mattas. 2006. The role of food quality certification on consumers' food choices. Br. Food J. 108:77-90. https://doi.org/10.1108/00070700610644906.

Busch, G., and A. Spiller. 2016. Real farmer share, perceived farmer share and fair distribution in food chains from a consumers' perspective. J. Econ. Psychol. 55:149-158. https://doi.org/10.1016/j. joep.2016.03.007.

Cardoso, C. S., M. J. Hötzel, D. M. Weary, J. A. Robbins, and M. A. G. von Keyserlingk. 2016. Imagining the ideal dairy farm. J. Dairy Sci. 99:1663-1671. https://doi.org/10.3168/jds.2015-9925.

Carrigan, M., and A. Attalla. 2001. The myth of the ethical consumer-Do ethics matter in purchase behaviour? J. Consum. Mark. 18:560-578. https://doi.org/10.1108/07363760110410263.

Charlebois, S., and S. Haratifar. 2015. The perceived value of dairy product traceability in modern society: An exploratory study. J. Dairy Sci. 98:3514-3525. https://doi.org/10.3168/jds.2014-9247.

Cicia, G., and F. Colantuoni. 2010. Willingness to pay for traceable meat attributes: A meta-analysis. J. Food Syst. Dynamics 3:252263. https://doi.org/10.18461/ijfsd.v1i3.138.

Croissant, Y. 2013. Mlogit: Multinomial logit model. R package version 0.2-4. Accessed Jan. 28, 2016. http://CRAN.R-project.org/ package $=$ mlogit.

de Graaf, S., E. J. Van Loo, J. Bijttebier, F. Vanhonacker, L. Lauwers, F. A. M. Tuyttens, and W. Verbeke. 2016. Determinants of consumer intention to purchase animal-friendly milk. J. Dairy Sci. https://doi.org/10.3168/jds.2016-10886.

Dehue, B., S. Meyer, and C. Hamelinck. 2007. Towards a Harmonised Sustainable Biomass Certification Scheme. Ecofys Netherlands BV, Utrecht.

Destatis. 2010. Landwirtschaftszählung 2010. Accessed Nov. 17, 2015. https://www.destatis.de.

Fairtrade. 2011. Explanatory document for the Fairtrade trade standard. Accessed May 20, 2016. http://www.fairtrade.net/fileadmin/ user_upload/content/2011-12-29_Explan_Doc_GTS_EN.pdf.

FSC (Forest Stewardship Council). 2011. FSC standard for Chain of Custody certification. Accessed Feb. 16, 2016. http://citeseerx.ist. psu.edu/viewdoc/download?doi=10.1.1.470.6687\&rep=rep1\&type $=$ pdf.

FSC (Forest Stewardship Council). 2016. Controlled wood. Accessed Feb. 16, 2016. https://ic.fsc.org/en/certification/types-ofcertification/controlled-wood-02.

Getter, K. L., B. K. Behe, D. S. Conner, and P. H. Howard. 2014 Pasture-raised milk: The market for a differentiated product. J. 
Food Prod. Mark. 20:146-161. https://doi.org/10.1080/10454446 .2012 .726949 .

Giannakas, K. 2002. Information asymmetries and consumption decisions in organic food product markets. Can. J. Agric. Econ. 50:3550. https://doi.org/10.1111/j.1744-7976.2002.tb00380.x.

Goovaerts, L., L. Pelkmans, C. S. Goh, M. Junginger, J. Joudrey, H. Chum, C. T. Smith, I. Stupak, A. Cowie, L. Dahlmann, O. Englund, and A. G. Eng. 2013. Strategic inter-task study: Monitoring sustainability certification of bioenergy, task 1: Examining sustainability certification of bioenergy. Accessed July 25, 2016. http:// www.bioenergytrade.org/downloads/iea-sust-cert-task-1-final2013. pdf.

Grunert, K. G. 2005. Food quality and safety: Consumer perception and demand. Eur. Rev. Agric. Econ. 32:369-391. https://doi. org/10.1093/eurrag/jbi011.

Heerwagen, L. R., M. R. Morkbak, S. Denver, P. Sandoe, and T. Christensen. 2015. The role of quality labels in market-driven animal welfare. J. Agric. Environ. Ethics 28:67-84. https://doi. org/10.1007/s10806-014-9521-z.

Hensher, D. A., and W. H. Greene. 2003. The mixed logit model: The state of practice. Transportation 30:133-176.

Hernandez-Mendo, O., M. A. G. von Keyserlingk, D. M. Veira, and D. M. Weary. 2007. Effects of pasture on lameness in dairy cows. J. Dairy Sci. 90:1209-1214. https://doi.org/10.3168/jds.S00220302(07)71608-9.

Honkanen, P., B. Verplanken, and S. O. Olsen. 2006. Ethical values and motives driving organic food choice. J. Consum. Behav. 5:420430. https://doi.org/10.1002/cb.190.

Jones, P., C. Clarke-Hill, P. Shears, and D. Hillier. 2001. Retailing organic foods. Br. Food J. 103:358-365. https://doi. org/10.1108/00070700110396358.

Kim, Y. J., and W.-N. Lee. 2009. Overcoming consumer skepticism in cause-related marketing: The effects of corporate social responsibility and donation size claim objectivity. J. Promot. Manage. 15:465-483. https://doi.org/10.1080/10496490903270232.

Langen, N., C. Grebitus, and M. Hartmann. 2010. Is there needw for more transparency and efficiency in cause-related marketing? J. Food Syst. Dynamics 4:366-381. https://doi.org/10.18461/ijfsd. v1i4.148.

Laroche, M., J. Bergeron, and G. Barbaro-Forleo. 2001. Targeting consumers who are willing to pay more for environmentally friendly products. J. Consum. Mark. 18:503-520. https://doi.org/10.1108/ EUM0000000006155.

Laurent, G., and J.-N. Kapferer. 1985. Measuring consumer involvement profiles. J. Mark. Res. XXII:41-53. https://doi. org $/ 10.2307 / 3151549$

Louviere, J. J., D. A. Hensher, and J. D. Swait. 2000. Stated Choice Methods: Analysis and Application. Cambridge University Press, New York, NY.

Lusk, J. L., and T. C. Schröder. 2004. Are choice experiments incentive compatible? A test with quality differentiated beef steaks. Am. J. Agric. Econ. 86:467-482. https://doi.org/10.1111/j.00925853.2004.00592.x.

MAXQDA. 2016. Software for qualitative data analysis, 1989-2016, VERBI Software - Consult - Sozialforschung GmbH, Berlin, Gemany.

McEachern, M. G., and M. J. A. Schröder. 2002. The role of livestock production ethics in consumer values towards meat. J. Agric. Environ. Ethics 15:221-237. https://doi.org/10.1023/A:1015052816477.

Milchindustrie. 2015. Milch und mehr-Die deutsche Milchwirtschaft auf einen Blick. Accessed May 12, 2016. http://www. milchindustrie.de/fileadmin/Dokumente/Verband/Fakten_ Journalist_Sept_2015.pdf.

Nehring, R., J. Sauer, J. Gillespie, and C. Hallahan. 2016. United States and European dairy farms: Where is the competitive edge? Int. Food Agribus. Manage. 19:219-240.

OECD (Organisation for Economic Co-Operation and Development). 2004. Organic dairy production-Policy measures and market developments. Pages 155-174 in Agriculture, Trade and the Environment: The Dairy Sector. OECD Publications, Pris, France.
Padel, S., and C. Foster. 2005. Exploring the gap between attitudes and behavior-Understanding why consumers buy or do not buy organic food. Br. Food J. 107:606-625. https://doi. org/10.1108/00070700510611002.

Pirog, R. S. 2004. Consumer perceptions of pasture-raised beef and dairy products: An Internet consumer study. Accessed Mar. 16, 2017. http://lib.dr.iastate.edu/cgi/viewcontent.cgi?article $=1134 \&$ context=leopold_pubspapers.

R Core Team. 2015. R: A language and environment for statistical computing. Accessed Apr. 18, 2016. http://www.R-project.org/.

Reijs, J. W., C. H. G. Daatselaar, J. F. M. Helming, J. Jager, and A. C. G. Beldman. 2013. Grazing dairy cows in North-West Europe. LEI Report 2013-001. LEI Wageningen UR, the Hague, the Netherlands.

RSPO (Roundtable on Sustainable Palm Oil). 2016. Smallholders. Accessed May 12, 2016. http://www.rspo.org/smallholders.

Schären, M., S. Jostmeier, S. Ruesink, L. Hüther, J. Frahm, M. Bulang, U. Meyer, J. Rehage, J. Isselstein, G. Breves, and S. Dänicke. 2016. The effects of a ration change from a total mixed ration to pasture on health and production of dairy cows. J. Dairy Sci. 99:1183-1200. https://doi.org/10.3168/jds.2015-9873.

Schreiner, J. A., and U. Latacz-Lohmann. 2015. Farmers' valuation of incentives to produce genetically modified organism-free milk: Insights from a discrete choice experiment in Germany. J. Dairy Sci. 98:7498-7509. https://doi.org/10.3168/jds.2015-9515.

Schröder, M. J. A., and M. G. McEachern. 2004. Consumer value conflicts surrounding ethical food purchase decisions: A focus on animal welfare. Int. J. Consum. Stud. 28:168-177. https://doi. org $/ 10.1111 / \mathrm{j} .1470-6431.2003 .00357 . x$

Schulze, B., and A. Spiller. 2008. Wer kauft noch an der Theke? Ergebnisse einer Verbraucherstudie zu SB-Fleisch. Pages 19-28 in Agrarund Ernährungswirtschaft im Umbruch, Schriften der Gesellschaft für Wirtschafts- und Sozialwissenschaften des Landbaues e.V. Vol. 43. Landwirtschaftsverlag, Münster-Hiltrup, Germany.

Schuman, H., and S. Presser. 1981. Questions and Answers in Attitude Surveys: Experiments on Question Form, Wording and Context. Academic Press, New York, NY.

Schuppli, C. A., M. A. G. von Keyserlingk, and D. M. Weary. 2014. Access to pasture for dairy cows: Responses from an online engagement. J. Anim. Sci. 92:5185-5192. https://doi.org/10.2527/ jas.2014-7725.

Sheikh, S. R., and R. Beise-Zee. 2011. Corporate social responsibility or cause-related marketing? The role of cause specificity of CSR. J. Consum. Mark. 28:27-39. https://doi. org /10.1108/07363761111101921.

Statista. 2016. Durchschnittsalter der Bevölkerung in den wichtigsten Industrie- und Schwellenländern im Jahr 2015. Accessed Jan. 28, 2016. http://de.statista.com/statistik/daten/studie/37220/ umfrage/altersmedian-der-bevoelkerung-in-ausgewaehltenlaendern/.

Statistisches Bundesamt. 2015a. Einnahmen und Ausgaben privater Haushalte-Fachserie 15 Heft 4-2013. Accessed Jan. 28, 2016. https://www.destatis.de/DE/Publikationen/Thematisch/ EinkommenKonsumLebensbedingungen/EinkommenVerbrauch/ EVS_EinnahmenAusgabenprivaterHaushalte.html.

Statistisches Bundesamt. 2015b. Statistisches Jahrbuch 2015. Accessed Jan. 28, 2016. https://www.destatis.de/DE/Publikationen/ StatistischesJahrbuch/StatistischesJahrbuch.html.

Swait, J. 2006. Advanced choice models. Pages 229-293 in Valuing Environmental Amenities Using Stated Choice Studies. B. J. Kanninen, ed. Springer, Dordrecht, the Netherlands.

Szmigin, I., M. Carrigan, and M. G. McEachern. 2009. The conscious consumer: Taking a flexible approach to ethical behavior. Int. J. Consum. Stud. 33:224-231. https://doi.org/10.1111/j.14706431.2009.00750.x

Tempesta, T., and D. Vecchiato. 2013. An analysis of the territorial factors affecting milk purchase in Italy. Food Qual. Prefer. 27:3543. https://doi.org/10.1016/j.foodqual.2012.06.005.

Thomas, D. R. 2006. A general inductive approach for analyzing qualitative evaluation Ddata. Am. J. Eval. 27:237-246. https://doi. org $/ 10.1177 / 1098214005283748$. 
Torjusen, H., G. Lieblein, M. Wandel, and C. A. Francis. 2001 Food system orientation and quality perception among consumers and producers of organic foods in Hedmark County, Norway. Food Qual. Prefer. 12:207-216. https://doi.org/10.1016/S09503293(00)00047-1.

Train, K. E. 2009. Discrete Choice Methods With Simulation. 2nd ed. University Press, New York.

Wangrakdiskul, U., and N. Yodpijit. 2012. Roundtable on Sustainable Palm Oil (RSPO) in smallholder farmers of Thailand. Pages 1-8 in Proceedings of the Asia Pacific Industrial Engineering and Management Systems Conference 2012. Phuket, Thailand, Dec. 2-5.

Weatherell, C., A. Tregear, and J. Allinson. 2003. In search of the concerned consumer: UK public perceptions of food, farming and buying local. J. Rural Stud. 19:233-244. https://doi.org/10.1016/ S0743-0167(02)00083-9.

Weinrich, R., A. Franz, and A. Spiller. 2015. Multi-level labelling: Too complex for consumers? Discussion Paper, Department for Agricultural Economy and Rural Development, University of Goettingen, Germany, No. 1512

Weinrich, R., S. Kühl, A. Zühlsdorf, and A. Spiller. 2014. Consumer attitudes in Germany towards different dairy housing systems and their implications for the marketing of pasture raised milk. Int. Food Agribus. Manage. 17:205-222.

White, S. L., G. A. Benson, S. P. Washburn, and J. T. J. Green. 2002. Milk production and economic measures in confinement or pasture systems using seasonally calved Holstein and Jersey cows. J. Dairy Sci. 85:95-104. https://doi.org/10.3168/jds.S0022-0302(02)740575.

Wolf, C. A., G. T. Tonsor, M. G. S. McKendree, D. U. Thomson, and J. C. Swanson. 2016. Public and farmer perception of dairy cattle welfare in the United States. J. Dairy Sci. 99:5892-5903. https:// doi.org/10.3168/jds.2015-10619.

Wolf, C. A., G. T. Tonsor, and N. J. Olynk. 2011. Understanding U.S. consumer demand for milk production attributes. J. Agric. Resour. Econ. 36:326-342.

Zhang, C., and F. H. Conrad. 2014. Speeding in web surveys: The tendency to answer very fast and its association with straightlining. Surv. Res. Methods 8:127-135. https://doi.org/10.18148/ srm/2014.v8i2.5453. 